\title{
Erratum to: ICF, quality of life, and depression in breast cancer: perceived disability in disease-free women 6 months after mastectomy
}

\author{
Anna Giardini • Camilla Pisoni • Ines Giorgi • \\ Veronica Borelli • Elisabetta Scoccia • Giuseppina Majani
}

Published online: 3 August 2013

(C) Springer-Verlag Berlin Heidelberg 2013

Erratum to: Support Care Cancer (2013) 21:2453-2460

DOI 10.1007/s00520-013-1794-7

The original version of this article unfortunately contained mistakes. The names of all authors were inadvertently inverted and are now corrected in the author group of this article.

The online version of the original article can be found at http://dx.doi.org/ 10.1007/s00520-013-1794-7.

A. Giardini $(\bowtie) \cdot$ C. Pisoni $\cdot$ G. Majani

Servizio di Psicologia, Istituto Scientifico di Montescano (PV),

Fondazione Salvatore Maugeri-IRCCS, via per Montescano,

27040 Montescano, Italy

e-mail: anna.giardini@fsm.it

I. Giorgi $\cdot$ V. Borelli

Servizio di Psicologia, Istituto Scientifico di Pavia, Fondazione

Salvatore Maugeri-IRCCS, via Maugeri,

27100 Pavia, Italy

E. Scoccia

Chirurgia Senologica, Istituto Scientifico di Pavia, Fondazione

Salvatore Maugeri-IRCCS, via Maugeri Fondazione,

27100 Pavia, Italy 